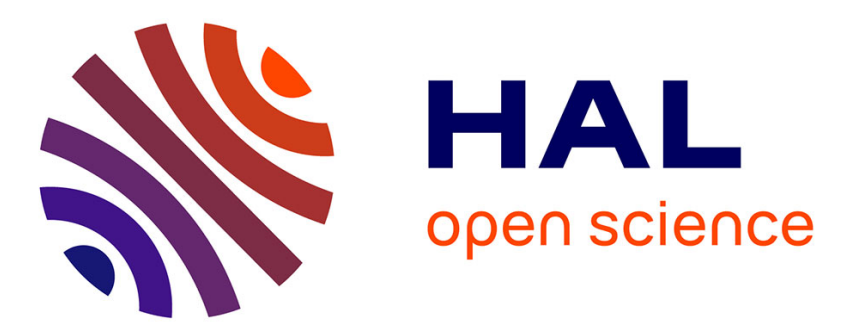

\title{
Prediction of the unsteady turbulent flow in an axial compressor stage. Part 1: Comparison of unsteady RANS and LES with experiments
}

Nicolas Gourdain

\section{- To cite this version:}

Nicolas Gourdain. Prediction of the unsteady turbulent flow in an axial compressor stage. Part 1: Comparison of unsteady RANS and LES with experiments. Computers and Fluids, 2015, vol. 106, pp. 119-129. 10.1016/j.compfluid.2014.09.052 . hal-01104725

\section{HAL Id: hal-01104725 \\ https://hal.science/hal-01104725}

Submitted on 19 Jan 2015

HAL is a multi-disciplinary open access archive for the deposit and dissemination of scientific research documents, whether they are published or not. The documents may come from teaching and research institutions in France or abroad, or from public or private research centers.
L'archive ouverte pluridisciplinaire HAL, est destinée au dépôt et à la diffusion de documents scientifiques de niveau recherche, publiés ou non, émanant des établissements d'enseignement et de recherche français ou étrangers, des laboratoires publics ou privés. 


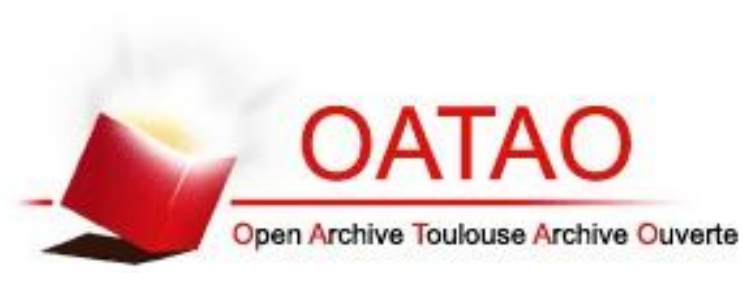

\section{Open Archive Toulouse Archive Ouverte (OATAO)}

OATAO is an open access repository that collects the work of Toulouse researchers and makes it freely available over the web where possible.

This is an author-deposited version published in: http://oatao.univ-toulouse.fr/ Eprints ID: 12304

To link to this article: DOI: $10.1016 / j . c o m p f l u i d .2014 .09 .052$

URL: http://dx.doi.org/10.1016/j.compfluid.2014.09.052

To cite this version: Gourdain, Nicolas Prediction of the unsteady turbulent flow in an axial compressor stage. Part 1: Comparison of unsteady RANS and LES with experiments. (2015) Computers and Fluids, vol. 106 . pp. 119-129. ISSN 0045-7930

Any correspondence concerning this service should be sent to the repository administrator: staff-oatao@inp-toulouse.fr 


\title{
Prediction of the unsteady turbulent flow in an axial compressor stage. Part 1: comparison of unsteady RANS and LES with experiments.
}

\author{
Nicolas Gourdain \\ CERFACS, Computational Fluid Dynamics Team, Toulouse, France \\ ISAE, Dpt. of Aerodynamics, Energetics and Propulsion, Toulouse, France \\ Email: Nicolas.Gourdain@isae.fr, Phone: +33561339255
}

\begin{abstract}
A better understanding of turbulent unsteady flows is a necessary step towards a breakthrough in the design of modern gas turbine components. With the increase in computing power, LES emerges as a promising method to improve both knowledge of complex physics and reliability of flow solver predictions. However, there is still a lack of evidences in the literature that LES is applicable for turbomachinery at conditions relevant to industrial applications. In that context, the objective of the present work is to investigate the capability of LES to predict the turbulent flow in a stage of an axial compressor and compare the results with unsteady RANS data and experiments. The compressor operates at industrial relevant conditions, with Mach and Reynolds numbers equal to $M=0.5$ and $R e=7 \times 10^{5}$, respectively. This paper presents the numerical method and a comparison of URANS and LES results to experimental data. A particular care is brought to estimate the results sensitivity to grid refinement (LES) and to turbulence and transition
\end{abstract}


modelling (URANS). The comparison to experiments shows that LES better predicts time-dependent quantities than URANS, especially close to the casing. However, both URANS and LES fail to accurately estimate the compressor performance (efficiency and pressure ratio).

Keywords: Large-Eddy Simulation, unsteady RANS, compressor stage 


\section{Nomenclature}

\begin{tabular}{|c|c|}
\hline Latin & Greek, symbols and acronyms \\
\hline$C$ :Blade chord & $\delta:$ Boundary layer thickness \\
\hline$h:$ Radial height & $\eta$ :Efficiency \\
\hline$H$ :Compressor vein height & $\eta_{K}:$ Kolmogorov length scale \\
\hline$k:$ Turbulent kinetic energy & $\epsilon$ :Dissipation \\
\hline$M$ :Mach number & $\tau:$ Stress tensor \\
\hline$M_{0,1,2}:$ Type of grid (see Table 2 ) & $\pi:$ Total-to-total pressure ratio \\
\hline$n:$ Normal to the wall component & $\nu:$ Kinematic viscosity \\
\hline$p:$ Pressure & $\theta$ :Azimuthal direction, momentum thickness \\
\hline$Q$ :Mass flow & $\omega:$ Compressor rotation speed \\
\hline$r:$ Radial component/direction & $\cdot S G S$ :Sub-grid scale \\
\hline Re :Reynolds number & $\cdot_{0}$ :Inlet value \\
\hline$s:$ Streamwise component & $\cdot_{2}$ :Outlet value \\
\hline$S$ :Curvilinear abscissa or entropy & $\cdot^{+}:$Normalized value at the wall \\
\hline$S_{i j}:$ Strain rate tensor & ? :Resolved field \\
\hline$T:$ Temperature & BPF:Blade Passing Frequency \\
\hline$T u$ :Turbulent intensity $\left(\sqrt{W_{i}^{\prime 2}} /\|W\|\right)$ & LES:Large-Eddy Simulation \\
\hline$W$ :Velocity component (relative frame) & RANS:Reynolds Averaged Navier-Stokes \\
\hline$x$ :Axial direction & RMS:Root Mean Square quantity \\
\hline
\end{tabular}




\section{INTRODUCTION}

The design of efficient gas turbines requires a better prediction of the components performance and understanding of unsteady flows. Among all components, the compressor remains a critical part of a gas turbine, especially regarding its efficiency and stability. Due to the adverse pressure gradient, the flow in this component is unstable by nature and complex flow instabilities such as surge or rotating stall can occur [10], potentially leading to mechanical failure. In that context, maximizing the efficiency of compressors is particularly complex. First, overall performance is largely impacted by the matching conditions between the successive rotor and stator rows ("timeaveraged" flow effects). For instance, rotor tip clearance variations and endwall flows affect both efficiency [12] and aerodynamic stability [9, 26]. Then, relative motions between fixed and rotating parts induce periodic unsteady flows that also modify overall performance, aerodynamic stability and the development of secondary flows $[2,3]$. The improvement of the compressor robustness and performance (for example by using control devices in the tip leakage region [24]) requires thus a better understanding of the flow physics that takes place in these systems.

Complementary to experimental investigations, the numerical simulation of flows, commonly referred to as Computational Fluid Dynamics (CFD), is a very promising way to investigate flows at real operating conditions. However it is still a challenge for CFD to predict the flow in industrial compressors. Such high Reynolds number flows imply a large range of turbulent flow scales 
that can not be properly resolved at the same time with current computing means, meaning turbulence modelling is necessary.

On the one hand, the Reynolds Averaged Navier-Stokes (RANS) formalism, which proposes to model all turbulent scales, is the most common and mature method. The unsteady RANS (URANS) approach is a natural extension of the RANS formalism to address unsteady flows, including nonperiodic flows such as aerodynamic instabilities [25, 21]. On the other hand, LES introduces the notion of scale separation by explicitly or implicitly spatially filtering the large unsteady flow motions from the small more universal turbulent flow scales. LES appears as a promising method to reduce the level of modelling and increase the reliability of CFD predictions [45, 42]. This is reflected by the numerous recent works dealing with LES applied to a wide range of turbomachinery problems, such as off-design operating conditions $[23,33]$, secondary flows $[53,6]$, heat transfer $[13,54,5,18]$ and aero-acoustics [22]. However, most works reported in the literature only deal with isolated rotor or stator geometries. Among the few works dealing with rotor/stator configurations [39, 33, 22, 44], most of them consider modified designs (blade rescaling, quasi-3D assumptions, etc.) or unresolved boundary layers (wall law approach, etc.) to reduce the computational cost. At this time, and except seldom works $[50,51]$, there is also a lack of recommendations about numerical methods and mesh requirements to apply LES to turbomachinery.

This paper presents the numerical methods, based on unsteady RANS 
and LES formalisms, to predict the unsteady turbulent flow in an axial compressor stage. For both approaches, the geometry takes into account for the whole 3D flow (including rotor tip clearance) and the real ratio between the number of rotor blades and stator vanes. This paper is organized in four sections. In the first section, the compressor test case is presented along with the CFD code. The computational domain and set of boundary conditions are detailed as well as the computational cost related to URANS and LES. The second section focuses on the evaluation of the sensitivity of LES results to the grid density, through the comparison of boundary layer profiles and production of turbulent kinetic energy with three different grids. In the third section, the influence of turbulence and transition modelling is evaluated on the URANS predictions. Last, a comparison between LES and URANS results is done with experimental measurements, with a particular emphasis on the dataset at nominal operating conditions.

\section{EXPERIMENTAL CONFIGURATION}

The test case is the CME2 compressor, originally investigated at the LEMFI laboratory $[14,36]$ and now located at the Fluid Mechanics Institute of Lille (France). This axial compressor is designed by SNECMA to provide representative unsteady rotor-stator interactions encountered in modern high-pressure compressors. Fig. 1 shows a view of the compressor and the dashed box pointed out the simulated part of the machine. Four struts are also located upstream the compressor at the entrance of the inlet duct. The 
outer tip radius is $0.275 \mathrm{~m}$ and the tip clearance represents $0.8 \%$ of the rotor span. Table 1 gives some information about the geometry of the compressor. The nominal rotation speed is $6,330 \pm 14 \mathrm{rpm}$, which corresponds to a relative Mach number at tip of 0.53. The Reynolds number based on the rotor chord and the rotor exit velocity at mid-span is about 700,000. At the nominal operating point, the mass flow $Q$ is $10.50 \pm 0.1 \mathrm{~kg} . \mathrm{s}^{-1}$, the total-to-total pressure ratio $\pi$ is 1.15 and the isentropic efficiency $\eta$ is 0.92 .

The ratio between the numbers of rotor blades and stator vanes allows to consider only a tenth of the configuration without modification of the geometry. This compressor has been largely used for CFD-based studies, such as off-design flows [16], aero-acoustics [11] and control [19].

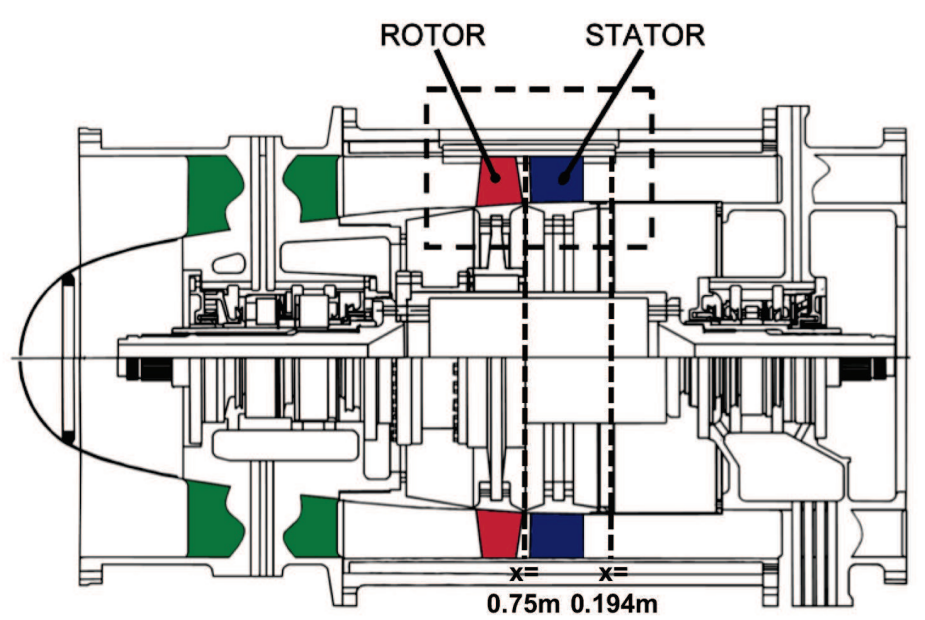

Figure 1: Axial view of the experimental compressor CME2. The plane at $x=75 \mathrm{~mm}$ is located at $18 \%$ of the rotor chord downstream the rotor and the plane at $x=194 \mathrm{~mm}$ is located at $50 \%$ of the stator chord downstream the stator. 
Table 1: Characteristics of the CME2 test case.

\begin{tabular}{cc}
\hline Blade passing frequency $f_{B P F}$ & $3,165 \mathrm{~Hz}$ \\
Tip rotor speed $(\omega R)_{\text {tip }}$ & $182.0 \mathrm{~m} \cdot \mathrm{s}^{-1}$ \\
Number of rotor blades $N_{R}$ & 30 \\
Number of stator vanes $N_{S}$ & 40 \\
Rotor blade chord & $84 \mathrm{~mm}$ \\
Stator blade chord & $77 \mathrm{~mm}$ \\
Axial gap (mid-span) & $20 \mathrm{~mm}$ \\
Tip clearance & $0.5 \mathrm{~mm}$ \\
Hub to tip ratio & 0.78 \\
\hline
\end{tabular}

\section{TOOLS AND METHOD}

\section{Governing equations}

The governing equations are the unsteady compressible Navier-Stokes equations that describe the conservation of mass, momentum and energy. The fluid follows the ideal gas law $p=\rho r T$, where $r$ is the mixture gas constant. The fluid viscosity follows Sutherland's law and the heat flux follows Fourier's law. For LES, the separation of scales is obtained by filtering out the small flow scales that can not be properly represented by the mesh, their effects on the filtered field being modelled by the so-called Sub-GridScale (SGS) model. LES involves the spatial Favre filtering operation that reduces for spatially, temporally invariant and localised filter functions to

$$
\widetilde{f(\mathbf{x}, t)}=\frac{1}{\overline{\rho(\mathbf{x}, t)}} \int_{-\infty}^{+\infty} \rho\left(\mathbf{x}^{\prime}, t\right) f\left(\mathbf{x}^{\prime}, t\right) G\left(\mathbf{x}^{\prime}-\mathbf{x}\right) d \mathbf{x}^{\prime}
$$


where $G$ denotes the box filter function ( $G=1$ for spatial wavelengths $\lambda>\lambda_{c}$ else $G=0)$. The value of $\lambda_{c}$ depends explicitly on the mesh dimensions. The unresolved SGS stress tensor $\overline{\tau_{i j}} S G S$ is modelled using the Boussinesq assumption [48]

$$
\begin{gathered}
\bar{\rho} \tau_{i j}^{S G S}=2 \bar{\rho} \nu_{S G S} \widetilde{S}_{i j}, \\
\text { with } \widetilde{S}_{i j}=\frac{1}{2}\left(\frac{\partial \widetilde{u}_{i}}{\partial x_{j}}+\frac{\partial \widetilde{u}_{j}}{\partial x_{i}}\right) .
\end{gathered}
$$

In Eq. (2), $\widetilde{S}_{i j}$ is the resolved strain rate tensor and $\nu_{S G S}$ is the SGS turbulent viscosity. The SGS energy flux ${\overline{q_{i}}}^{t}$ is modelled using a SGS turbulent heat conductivity obtained from $\nu_{S G S}$ by $\lambda_{t}=\bar{\rho} \nu_{t} / P r_{t}$ where $P r_{t}=0.9$ is a constant turbulent Prandtl number. The value for $P r_{t}$ is chosen arbitrarily but its effect can be minimized by resolving properly the boundary layers, so the turbulent contribution can be neglected in the viscous sub-layer provided that the SGS model has the appropriate behavior (close to walls, $\nu_{S G S} \approx 0$ ).

Compared to LES, the RANS strategy is based on the modeling of all the turbulent scales. The Reynolds stress tensor $\tau_{i j}{ }^{R A N S}$ in the RANS equations is expressed as (using the Boussinesq eddy viscosity assumption)

$$
\bar{\rho} \tau_{i j}^{R A N S}=2 \bar{\rho} \nu_{t} \widetilde{S_{i j}}-\frac{2}{3} \bar{\rho} k \delta_{i j}
$$

where $\nu_{t}$ is the turbulent viscosity and $k$ the turbulent kinetic energy, both provided by the turbulence model. 
Flow solver and numerical parameters

Both LES and (U)RANS equations are solved using the CFD code elsA. This software uses a cell centered approach on structured multiblock meshes. More information about the flow solver can be found in [8] for modeling capabilities and in [17] for High-Performance Computing capabilities.

For LES and URANS simulations, convective fluxes are computed with a third-order upwind scheme [38]. Diffusive fluxes are computed with a secondorder centered scheme. For URANS, two turbulence models will be compared to estimate the turbulent viscosity $\nu_{t}$ : the two equations model of Smith [49] based on a $k-l$ formulation and the two equations model of Menter [34] based on a $k-\omega$ formulation. The method to predict boundary layer transition is discussed in section 3. For LES, the subgrid scale model is the Wall-Adapting Local Eddy-Viscosity (WALE) model [37], specially built to compute the turbulence effects in wall bounded flows (the value of $\nu_{S G S}$ vanishes at walls).

The time-marching is ensured by a second order Dual Time Stepping method [27], which relies on an implicit scheme (with a scalar Lower-Upper Symmetric Successive Over-Relaxation -LU-SSOR- method [52]) and a Newton's algorithm for the inner loop (with about 10 sub-iterations per physical time step).

\section{Boundary conditions}

An injection condition is applied at the inlet with flow parameters based on experimental data $\left(P_{i, 0}=101,325 \mathrm{~Pa}, T_{i, 0}=288 \mathrm{~K}\right.$ and $\left.\alpha=0^{\circ}\right)$. To 
reduce the computational cost, the four struts located upstream and downstream the compressor are not meshed. Their influence on the inlet flow is thus taken into account through the turbulent intensity imposed at the inlet, $T u_{0}=2 \%$. Unfortunately, no information is available in the experiments about the turbulent length scale so the value is chosen arbitrarily, $l_{0}=5 \mathrm{~mm}$ (i.e. $8 \%$ of the rotor span). For LES, the boundary condition relies on a simplified version of the Synthetic Eddy Method [28], which introduces some perturbations in the flow that mimic the effects of turbulence. This method has been implemented in the code els $A$ and validated for aerodynamic applications in turbomachinery [18]. Unfortunately, the turbulent dissipation is sensitive to the grid quality with this approach. Other methods (not yet implemented in the present CFD flow solver) have been proposed in the literature (such as the precursor simulation [30]) which allows a more accurate control of the value for the freestream turbulent intensity.

At the outlet, a throttle condition is coupled with a simplified radial equilibrium to set the value of the static pressure $p_{s, 2}$ :

$$
p_{s, 2}(t)=p_{\text {ref }}+\lambda \cdot Q(t)^{2}
$$

with $p_{\text {ref }}$ a reference pressure (equals to the outside total pressure, 101,325 Pa) and $\lambda$ the so-called throttle parameter that set the operating point (an increase of this parameter mimic the effect of a reduction of the throttle section, moving the operating point towards a lower mass flow). This boundary con- 
dition is time-dependent (in the case of steady-RANS calculations, the value of the mass flow $Q$ is updated at each iteration until it reaches a steady-state at convergence). To avoid spurious waves at the outlet, the exit is located at 1.5 chord downstream the stator trailing edge and the mean size of grid cells is enlarged when approaching the outlet (in order to increase dissipation). This approach leads to an overload of the mesh size (by about $5 \%$ ) but it allows an accurate control of the operating point (the relaxation parameter considered in classical non-reflective boundary conditions usually results in a drift of the operating point).

Walls are considered as adiabatic and a condition of periodicity is used for lateral sections. It means that no spatial wavelength higher than the spatial periodicity of the configuration, $2 \pi / 10$, can develop, which forces the periodicity of unsteady flow patterns. The set of equations is solved in the relative frame of each row, meaning a dedicated boundary condition is needed to exchange information between the rotor and stator meshes. The method relies on the so-called "sliding mesh" technique [15]. A polygon clipping is performed between the two sliding parts of the mesh at each time step (and stored to be reused to reduce the computational time) and thus it ensures the conservation of the exchanged fluxes (on a planar interface).

\section{Mesh grid and time step}

The flow domain is discretized with a multiblock approach, using an $\mathrm{O}-\mathrm{H}$ meshing strategy for each passage. The mesh extends up to one rotor chord 
uptream and 1.5 stator chord dowstream the bladed region. The numerical domain consists in three rotor blades and four stator vanes, in order to respect the compressor periodicity. For both URANS and LES, the mesh represents the whole 3D domain, including the tip gap. Three meshes are built: grid M0 (the coarsest one), M1 and M2 (the finest one). All URANS simulations are performed on grid M0 and LES are performed with the three grids, in order to check the influence of grid refinement on the quality of results.

Information about grid dimensions are given in Table 2 (number of points) and Table 3 (normalized cell dimensions at the wall in the streamwise $\Delta \overline{s^{+}}$, normal-to-the-wall $\overline{n^{+}}$and radial $\Delta \overline{r^{+}}$directions). To compare with the present grids, the mesh criteria recommended in the literature to run a wallresolved LES [41, 31] are to use $50<\Delta \overline{s^{+}}<150, n^{+}<1$ and $15<r^{+}<40$.

Table 2: Number of points per blade passage, in the rotor tip gap and total for the whole configuration.

\begin{tabular}{ccccc}
\hline & Rotor & Rotor tip gap & Stator & Whole domain \\
\hline Mesh M0 & $1.99 \times 10^{6}$ & $95 \times 25 \times 41$ & $1.69 \times 10^{6}$ & $12.72 \times 10^{6}$ \\
Mesh M1 & $15.95 \times 10^{6}$ & $189 \times 49 \times 81$ & $13.52 \times 10^{6}$ & $101.93 \times 10^{6}$ \\
Mesh M2 & $126.83 \times 10^{6}$ & $377 \times 97 \times 161$ & $107.55 \times 10^{6}$ & $857.28 \times 10^{6}$ \\
\hline
\end{tabular}

The minimum cell size at walls is set to $5 \mu \mathrm{m}$ for grid M0 $\left(\overline{n^{+}} \approx 1.4\right)$ and $2 \mu \mathrm{m}\left(\overline{n^{+}} \approx 0.65\right)$ for grid M1 and M2, respectively. Grid M0 is fine enough to provide grid independent results for URANS. The evolution around rotor and stator walls of normalized grid dimensions $\Delta s^{+}, n^{+}$and $\Delta r^{+}$is represented in Fig. 2. Mesh criteria recommended in the literature to run wall-resolved 
Table 3: Typical grid dimensions at wall (streamwise $s$, normal $n$ and radial $r$ directions).

\begin{tabular}{lccc|ccc}
\hline & \multicolumn{3}{c|}{ ROTOR } & \multicolumn{3}{c}{ STATOR } \\
\hline & $\Delta \overline{s^{+}}$ & $\overline{n^{+}}$ & $\Delta \overline{r^{+}}$ & $\Delta \overline{s^{+}}$ & $\overline{n^{+}}$ & $\Delta \overline{r^{+}}$ \\
\hline Mesh M0 & 385 & 1.40 & 85 & 330 & 1.10 & 65 \\
Mesh M1 & 180 & 0.65 & 40 & 150 & 0.50 & 30 \\
Mesh M2 & 90 & 0.65 & 20 & 75 & 0.50 & 15 \\
\hline
\end{tabular}

LES are satisfied only with grid M2.

(a)

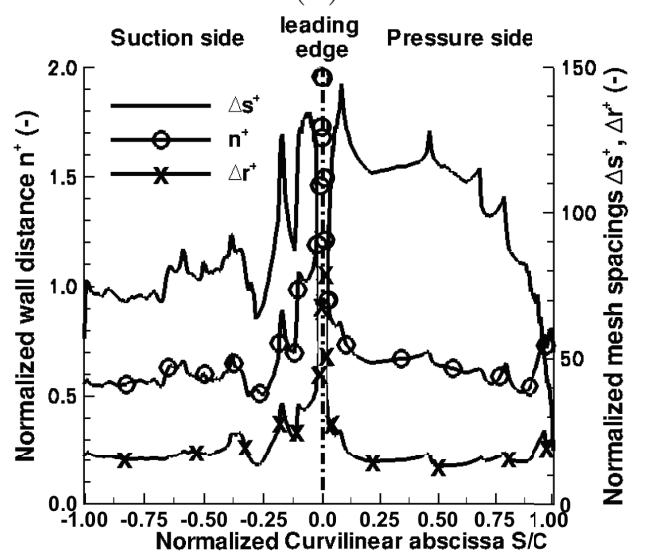

(b)

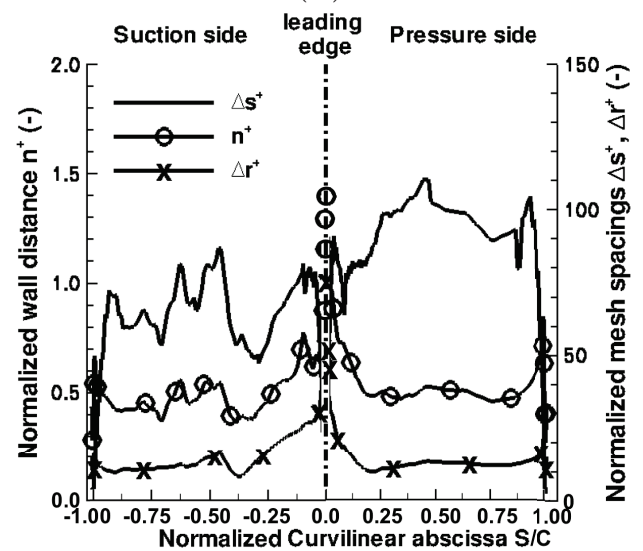

Figure 2: Averaged grid dimensions at wall (LES on mesh M2) around (a) rotor blade and (b) stator vane.

The time step is adapted to the mesh resolution at walls: $\Delta t^{+}=\Delta t \times$ $f_{B P F}$ is set to 0.0025 (i.e. $\Delta t=7.90 \times 10^{-7} \mathrm{~s}, 400$ time steps per rotor blade passing period) for the simulations on grid M0 and to 0.00125 (i.e. $\Delta t=$ $3.95 \times 10^{-7} \mathrm{~s}, 800$ time steps per rotor blade passing period) for simulations on grids M1 and M2, respectively. In all cases, the maximum CFL number, 
based on the cubic root of the cell volume, is lower than 12 .

\section{Estimation of the computation cost}

Table 4 shows the number of computation cores used for each simulation and the whole computational time (expressed in number of CPU hours ${ }^{1}$ necessary to perform one rotation of the compressor). The strategy used to reduce the cost of simulations is to run first URANS and use the final flow field to initialize LES (M0) and so on until LES (M2). The periodic state is achieved for URANS in 2 rotations at nominal operating conditions (4 rotations are necessary close to the stall limit). Then, LES (M0), LES (M1) and LES (M2) requires $1,0.5$ and 0.5 (respectively) rotation to converge statistics. The extraction of data for analysis is then performed on a full rotation for each of the three LES.

As shown in Table 4, the CPU cost is not proportional to the mesh and time step sizes. While the theoretical cost ratio from LES (M0) to LES (M1) should be $16(\times 8$ for the mesh size and $\times 2$ for the time step), it is close to 21. From LES (M0) to LES (M2), it is even worst since the CPU cost ratio is close to 570 instead of 128 . The boundary condition at the rotor/stator interface (the sliding mesh technique) is responsible for this overcost. First, the unbalance of the mesh cells associated to the boundary condition between all computational cores tends to minimize the speed-up [20]. Then, the whole

\footnotetext{
${ }^{1}$ the simulation is run on the BULL Intel Sandy Bridge supercomputer "Curie" of the "Très Grand Centre de Calcul du CEA".
} 
cost of the boundary condition directly depends on the number of cells at the rotor/stator interface (which increases roughly by a factor 4 at each mesh refinement), due to the cost of interpolations.

Table 4: Evaluation of the computation cost. The third line indicates the CPU cost to perform one rotation and the fourth one the cost of the whole simulation (including the time needed to extract data).

\begin{tabular}{ccccc}
\hline & $\begin{array}{c}\text { URANS } \\
(\mathrm{M} 0)\end{array}$ & $\begin{array}{c}\text { LES } \\
(\mathrm{M} 0)\end{array}$ & $\begin{array}{c}\text { LES } \\
(\mathrm{M} 1)\end{array}$ & $\begin{array}{c}\text { LES } \\
(\mathrm{M} 2)\end{array}$ \\
\hline Total number of rotations & 2 & 2 & 1.5 & 1.5 \\
Number of CPUs & 16 & 16 & 64 & 1,024 \\
Cost/rot. (CPUh) & 1,920 & 1,910 & 40,530 & $1,091,170$ \\
Total cost (CPUh) & 3,840 & 3,820 & 60,795 & $1,636,755$ \\
\hline
\end{tabular}

\section{INFLUENCE OF GRID DENSITY ON LES PREDICTIONS}

Figure 3 presents an instantaneous flow field shaded with density gradient $|\overrightarrow{\operatorname{grad} \rho}| / \rho$, extracted from LES on grid M2 close to the casing $(h / H=90 \%)$. This flow field shows an overview of the flow patterns that develop in the compressor: the tip leakage flow (close to the rotor suction side) generates very high turbulent activity that is then convected downstream, mixing with the rotor wakes and finally impacting the stator leading edge. The lower velocity in the wake (compared to the mean flow) forces the migration of turbulent flow patterns towards the stator pressure side (so a higher turbulent activity is expected on the vane pressure side than on the vane suction side). This picture indicates that a large range of scales exist in the flow (boundary 
layer vortices, inlet turbulence, wake vortices, tip leakage flow, etc.). Such difference of scales represent a big challenge to be properly computed with LES.

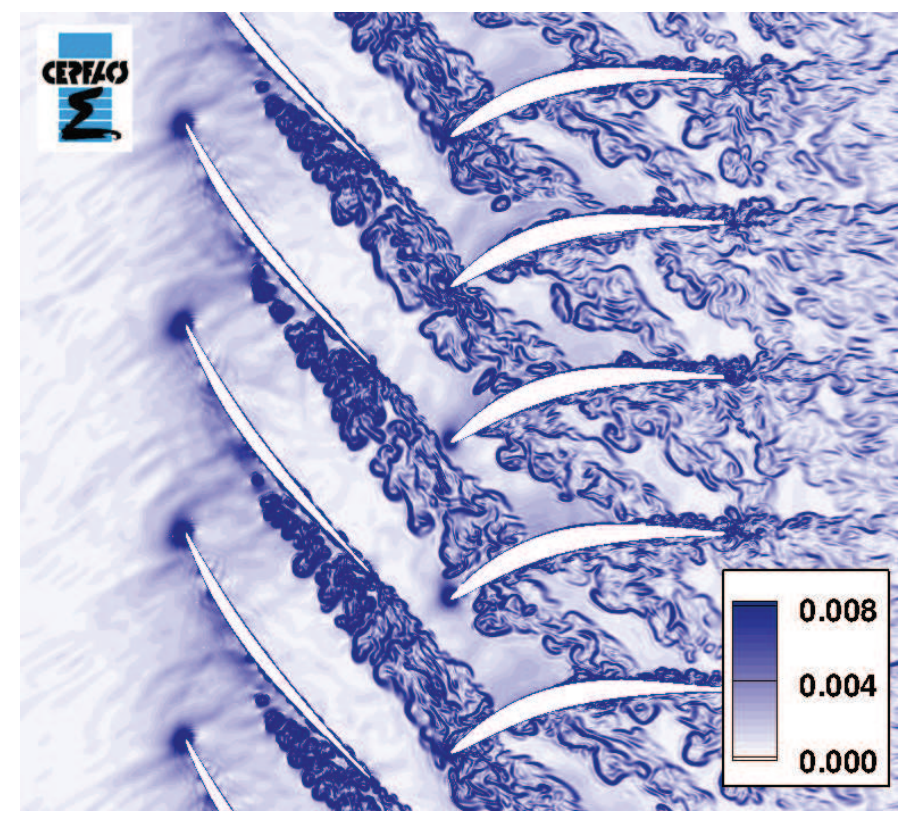

Figure 3: Instantaneous flow field shaded with density gradient $\operatorname{grad} \rho / \rho$ at $h / H=90 \%$ (LES, grid M2). Flow comes from left to right and rotor rotates from bottom to up.

The quality of LES results is evaluated by quantifying the effect of mesh density on the prediction of boundary layer profiles, Fig. 4. All data are time-averaged over one rotor revolution. Results presented in Fig. 4(a) indicate that LES (M1) and LES(M2) predicts the same value for the relative streamwise velocity $\overline{W_{S}}$ outside the boundary layer, while LES (M0) predicts a value higher by $2 \%$. Close to wall, the effect of grid refinement is more important: compared to LES on grid M2, LES on grid M0 under-estimates 
$\overline{W_{S}}$ by $60 \%$ at $n / \delta=0.10$.

(a)

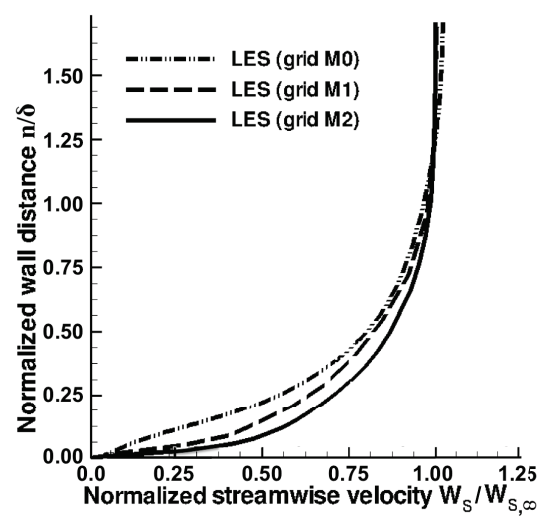

(b)

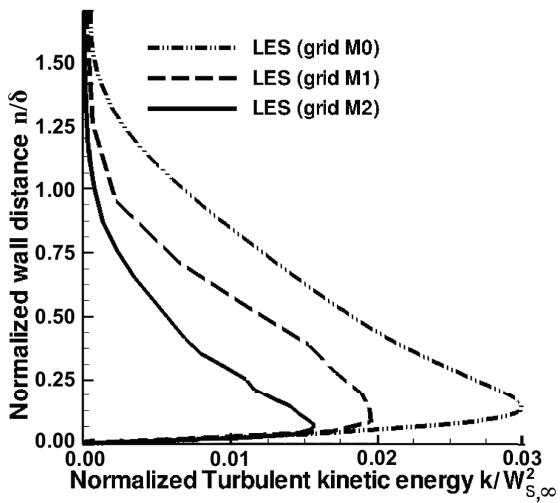

Figure 4: Influence of the mesh density on the time-averaged boundary layer profiles, rotor suction side at $h / H=50 \%$ and $S / C=80 \%$ : a) mean relative streamwise velocity $\overline{W_{S}}$ and b) mean resolved turbulent kinetic energy $\bar{k}$.

Fig. 4(b) compares the influence of grid density on the production of the time-averaged resolved turbulent kinetic energy $\bar{k}$, defined as:

$$
\bar{k}=\frac{1}{2}\left(\overline{w_{x}^{\prime 2}}+\overline{w_{\theta}^{\prime 2}}+\overline{w_{r}^{\prime 2}}\right) .
$$

The production of $\bar{k}$ is overestimated by LES (M0) and LES (M1) compared to LES (M2): LES (M0), respectively LES (M1), predict a peak $\bar{k}_{\max } / W_{S, \infty}^{2}=0.030$ (respectively $\bar{k}_{\max } / W_{S, \infty}^{2}=0.020$ ) at $n / \delta=0.15$ (respectively at $n / \delta=0.09)$. LES (M2) finds the maximum $\bar{k}_{\max } / W_{S, \infty}^{2}=0.016$ at $n / \delta=0.06$ (corresponding to $n^{+} \approx 40$ ). As reported in the literature [46], the maximum production of $k$, without pressure gradient, should be observed at $n^{+} \approx 10-20$. 
To check the quality of LES results in the boundary layers, Fig. 5 shows a comparison of the resolved $\epsilon_{R}$ and modeled $\epsilon_{S G S}$ parts of the dissipation tensor $\epsilon_{i j}$, defined as

$$
\epsilon_{i j}=2\left(\nu+\nu_{S G S}\right)<\widetilde{S}_{i j} \widetilde{S}_{i j}>
$$

Only the homogenous part of the scalar trace of the dissipation tensor is taken into account to evaluate $\epsilon$, which is a reasonable assumption as shown by Antonia et al. [43] (contribution of cross terms is neglected). The contribution of the resolved field to the total dissipation is obtained by computing separately $\bar{\epsilon}_{R}$ (due to natural flow viscosity $\nu$ ) and $\bar{\epsilon}_{S G S}$ (due to the viscosity provided by the model $\left.\nu_{S G S}\right)$.

The maximum value of the dissipation is located at the wall. The contribution of the model is negligible from $n / \delta=0$ (the SGS model ensures $\nu_{S G S}=0$ at walls) to $n / \delta=0.06$ where it reaches its maximum. Then from $n / \delta=0.06$ to $n / \delta=0.80$, the resolved $\bar{\epsilon}_{R}$ and the modeled $\bar{\epsilon}_{S G S}$ dissipations are of the same magnitude order. For $n / \delta>1.0$, the resolved contribution to the dissipation becomes higher by one order of magnitude.

The dissipation $\epsilon$, as defined in Eq. (7), and assuming $\epsilon \approx \frac{1}{3} \times \operatorname{tr}\left(\epsilon_{i j}\right)$, is used to estimate a pseudo-Kolmogorov length scale $\eta_{k}$, such as

$$
\eta_{k}=\left(\frac{\nu^{3}}{\epsilon}\right)^{\frac{1}{4}}
$$

To be accurate, the estimation of the Kolmogorov length scale $\eta_{k}$ requires 


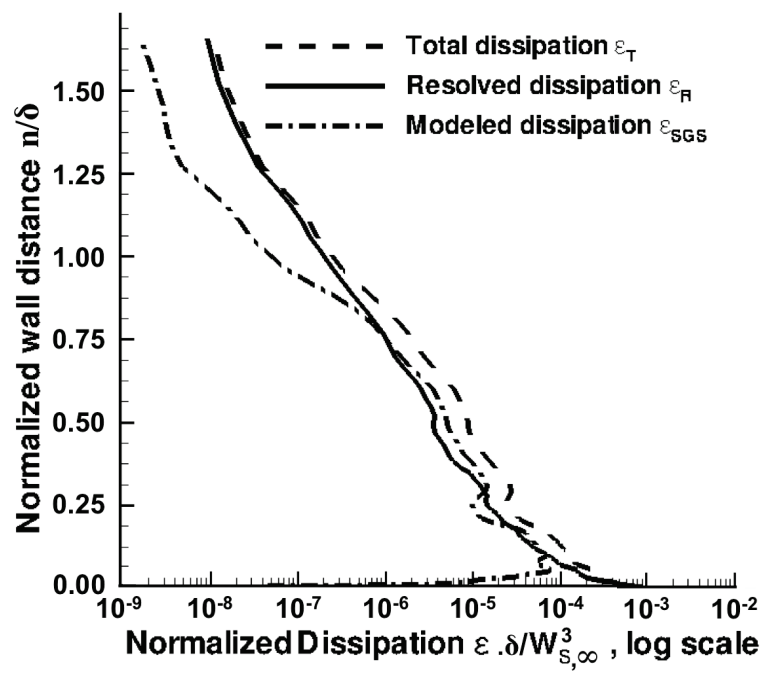

Figure 5: Comparaison of resolved, modelled and total dissipation $\epsilon$, suction side of the rotor at $h / H=50 \%$ and $S / C=80 \%$ (LES, grid M2).

the dissipation $\epsilon$ is computed by means of DNS data (and not LES data). However, in the present case, the contribution of the model (grid M2) is of the same magnitude order (or lower) than the contribution of the resolved field, so the magnitude order of the Kolmogorov length scale should be correct.

This pseudo-Kolmogorov length scale is then compared with the typical length scale of the meshes, defined as

$$
L_{m e s h}=\left(\Delta L_{s} \times \Delta L_{n} \times \Delta L_{r}\right)^{\frac{1}{3}},
$$

where $L_{i}$ is the size of the mesh cell in direction $i$.

The comparison between $L_{\text {mesh }}$ and $\eta_{k}$ is shown in Fig. 6. Close to the wall, the Kolmogorov length scale is found to be 2.5 times smaller than the 
typical mesh size of grid M2, $L_{\text {wall, } M 2}$, and 10 times smaller compared to $L_{\text {wall }, M 0}$. The difference rapidly decreases in the boundary layer and for $n / \delta>1.0$ (i.e. outside the boundary layer), the Kolmogorov length scale is of the same magnitude order than the typical size of mesh M2, $L_{M 2}$. This comparison confirms that LES on grid M2 properly resolves turbulent flow patterns, at least outside the boundary layer.

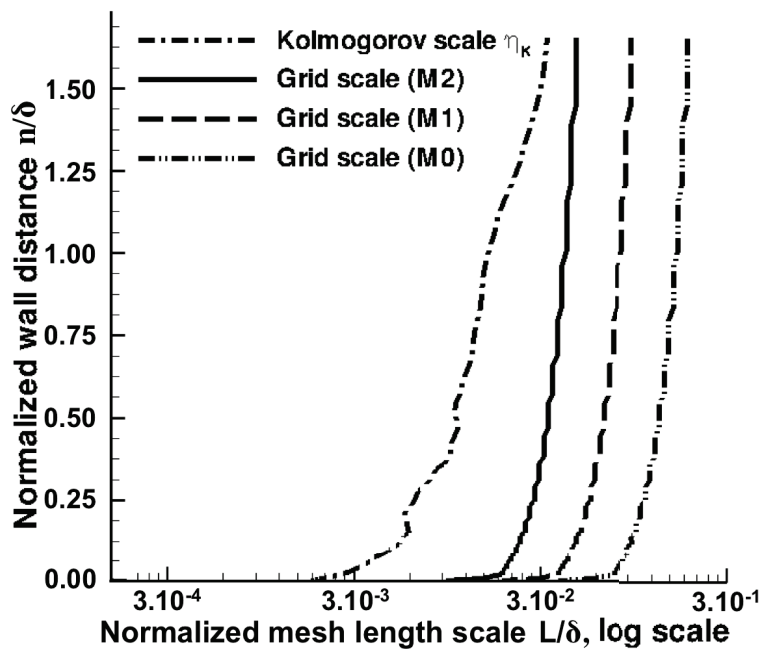

Figure 6: Comparaison of the Kolmogorov length scale $\eta_{k}$ with the mesh length scale normalized with the boundary layer thickness $\delta$, on the rotor suction side, at $h / H=50 \%$ and $S / C=80 \%$ (LES, grid M2).

Two conclusions are drawn from these results. First, the contribution of the model is still significant in a part of the boundary layer (it ensures half of the dissipation with grid M2 in the region $0.06<n / \delta<0.80)$, but it is found to be small outside of the boundary layers. Then, unfortunately, there 
is a lack of evidences that grid M2 is fine enough to provide grid-independent time-averaged statistics close to walls. In that regard, criteria recommended in the literature to run wall-resolved LES in academic configurations [41, 31] are probably not restrictive enough for turbomachinery flows (due to complex geometry walls and adverse pressure gradient).

\section{INFLUENCE OF TURBULENCE MODELLING ON URANS PRE- DICTIONS}

The accuracy of (U)RANS simulations largely relies on the turbulence modelling. The effects of the model onto the solution to the model is thus briefly studied by testing two first order models classicaly used for turbomachinery applications. Unsteady RANS simulations are performed with the $k-l$ turbulence model of Smith [49] and the $k-\omega$ model of Menter [34]. The whole performance curve of the compressor is described to evaluate the sensitivity of the solution to the turbulence modelling. Results are compared on Fig. 7(a) for the pressure ratio and Fig. 7(b) for the isentropic efficiency. The influence on pressure ratio and isentropic efficiency is small for largest mass flows (about $0.2 \%$ ), but it increases when approaching the stability limit. At nominal operating conditions, the difference on the isentropic efficiency is about $0.5 \%$ and it reaches $4 \%$ at near stall operating conditions $(Q=9.0 \mathrm{~kg} / \mathrm{s})$. Moreover, the stability limit is not predicted at the same mass flow (the criterion used to estimate the stability limit is the development of axial low frequencies, which are not correlated with the blade passing 
frequency, such as induced by rotating stall). The simulation with the $k-l$ model fails to achieve a periodic state below $Q=9.00 \mathrm{~kg} / \mathrm{s}$. The $k-\omega$ model predicts the last stable point at $Q=8.40 \mathrm{~kg} / \mathrm{s}$, which is closer to the value reported during the experimental campaign $(Q=8.57 \pm 0.09 \mathrm{~kg} / \mathrm{s})$.

(a)

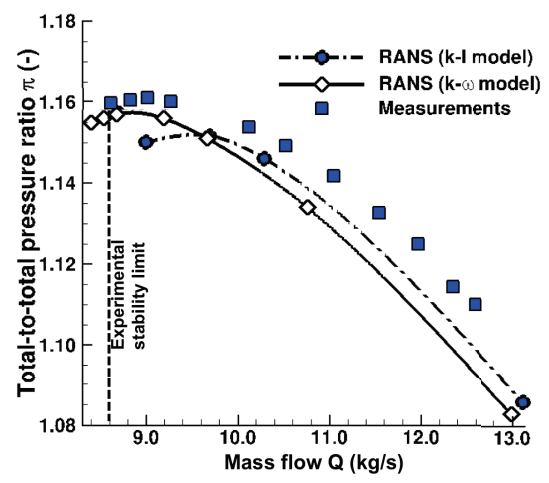

(b)

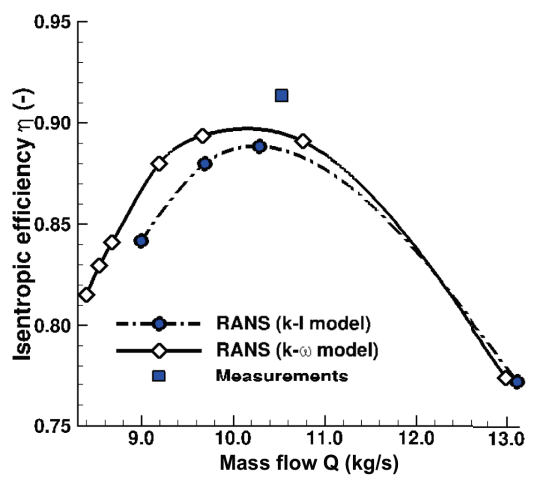

Figure 7: Unsteady RANS predictions of the compressor mean performance: a) total-tototal pressure ratio and b) isentropic efficiency. The experimental stability limit is found at $Q=8.57 \mathrm{~kg} \cdot \mathrm{s}^{-1}$.

Another source of uncertainty remains the state of boundary layers, for which there is no information in the experiments. Indeed, it has been chosen to compare the URANS prediction obtained with the $k-\omega$ turbulence model of Menter [34] without and with transition modelling. The method retained to detect transition is based on the work of Menter et al. [35] who proposed to use two transport equations for the intermittency factor $\gamma$ and the Reynolds number based on the transition momentum thickness $R e_{\theta, t}$. This method has been implemented and validated in the CFD flow solver els $A$ [4]. The prediction of the onset of laminar-to-turbulent transition is based on the 
correlations proposed by Langtry et al. [29], which improve the original AbuGhannam and Shaw [1] criterion at low turbulence level $(T u<3 \%)$ and represent a trade-off between the Abu Ghannam and Shaw and Mayle [32] correlations at higher turbulence level.

A simulation is run at nominal operating conditions $(Q \approx 10.5 \mathrm{~kg} / \mathrm{s})$ to highlight the effect of transition onto the numerical predictions. A comparison of the turbulent kinetic energy produced in the rotor and stator boundary layers is shown in Fig. 8, at a wall distance of $100 \mu \mathrm{m}$ (corresponding to $n / \bar{\delta} \approx 0.03$ ). Without transition criteria (fully turbulent boundary layer), the maximum production of turbulent kinetic energy $k$ is found at the leading edge, due to the high strain rate. Then the value of $k$ is decreasing along the wall and it reaches a minimum at the trailing edge. When transition effects are included in the simulation, transition occurs at $S / C=0.40$ on the rotor suction side and $S / C=0.30$ on the rotor pressure side. On the stator, transition spreads from $S / C=0$ to $S / C=0.45$ on the suction side and from $S / C=0$ to $S / C=0.25$ on the pressure side. The fact that transition occurs sooner on the stator pressure side is related to the migration towards the pressure side of the turbulent flow patterns contained in the rotor wake.

\section{COMPARISON WITH EXPERIMENTAL DATA}

The comparison of URANS and LES results is shown in Fig. 9(a) (pressure ratio $\pi$ ) and Fig. 9(b) (efficiency $\eta$ ). The whole performance characteristic is described with the URANS approach (without transition effects) and with 
(a)

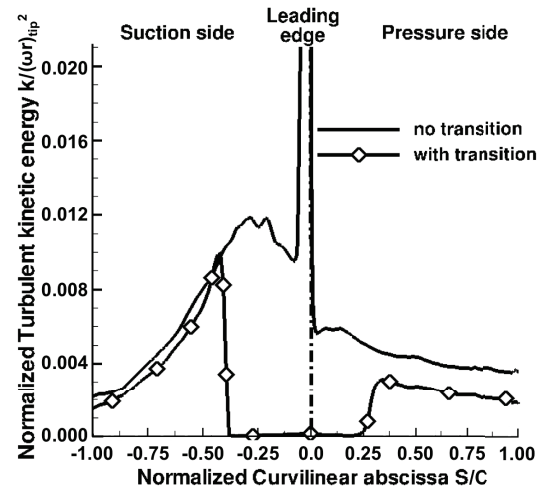

(b)

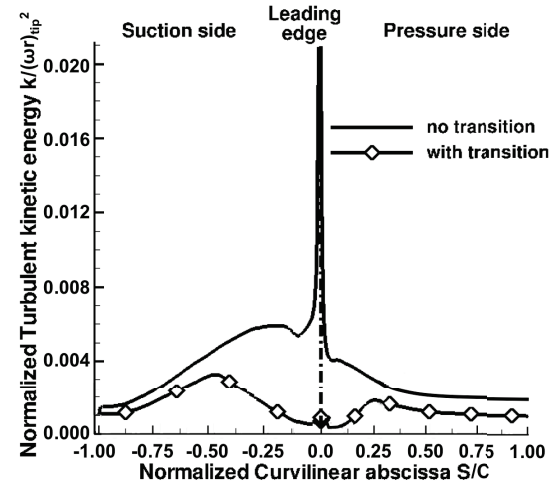

Figure 8: URANS predictions of the turbulent kinetic energy $k$ in the boundary layer, at a wall distance of $100 \mu m(n / \bar{\delta} \approx 0.03)$, at $h / H=50 \%$ : a) rotor blade and b) stator vane.

LES on grid M1. The shape of the isentropic efficiency curve predicted with URANS is steeper than the one predicted with LES. While URANS predicts a decrease by $8 \%$ of the efficiency from the nominal operating point to the last stable point, this decrease is only $3 \%$ with LES.

For the pressure ratio curve, both URANS and LES predicts a similar shape, which matches well with the shape of the experimental curve, except close to the stall limit where the decrease of the pressure ratio is more pronounced in the experiments. Both methods also predicts the same stability limit at $Q_{\text {stall }}=8.40 \mathrm{~kg} / \mathrm{s}$, which is close to the experimental value of $8.57 \mathrm{~kg} / \mathrm{s}$.

The performance at nominal operating conditions $(Q \approx 10.50 \mathrm{~kg} / \mathrm{s})$ are compared for five simulations, Table 5: three LES (on grids M0, M1 and M2) and two URANS calculations (without and with transition modelling). 
(a)

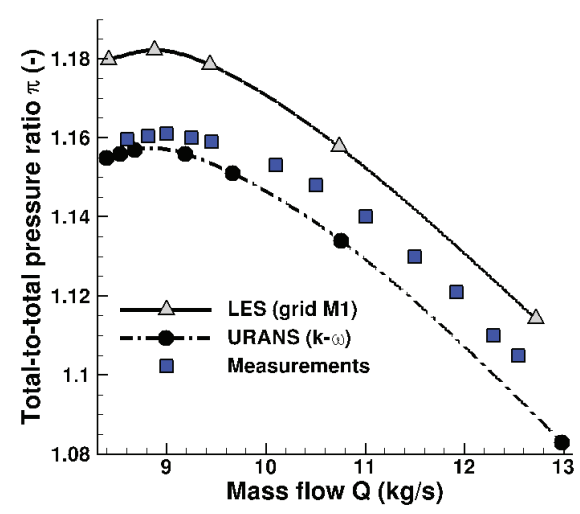

(b)

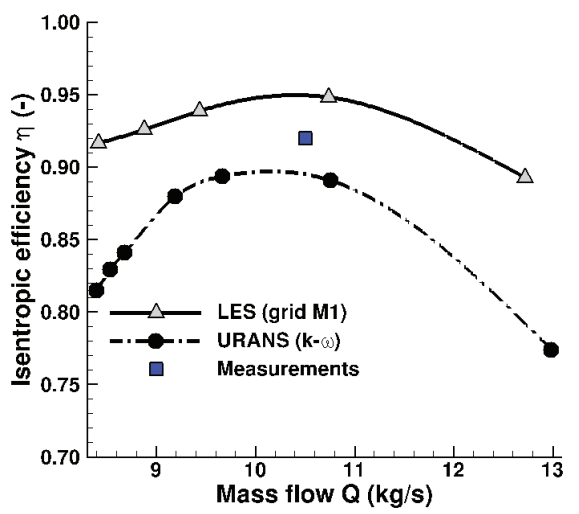

Figure 9: Mean performance of the compressor: a) pressure ratio $\pi$ and b) isentropic efficiency $\eta$.

As a general manner, URANS under-predicts the compressor performance while LES over-predicts it. When the transition effects are added in the URANS simulation, the results are closer to the LES ones, and close to the experimental values (differences on the pressure ratio and efficiency are resp. $0.05 \%$ and $0.75 \%$ ). The LES predictions for both pressure ratio and efficiency are also close to each other: from grid M0 to grid M2 the efficiency and pressure ratio increase by $0.45 \%$ and $0.10 \%$, respectively.

Three observations are noticed from this comparison: 1) transition effects have a strong influence on the performance predicted with URANS $(2.15 \%$ on the efficiency), 2) the effect of the grid density onto the performance predicted with LES is moderate (less than $0.5 \%$ on the efficiency from the 


\begin{tabular}{cccc}
- & Mass flow & Pressure ratio & Isentropic \\
& $\mathrm{Q}$ & $\pi$ & efficiency $\eta$ \\
\hline Experiments & $10.50 \mathrm{~kg} / \mathrm{s}$ & 1.150 & 0.92 \\
LES (grid M0) & $+1.80 \%$ & $+0.60 \%$ & $+2.50 \%$ \\
LES (grid M1) & $+2.30 \%$ & $+0.65 \%$ & $+2.80 \%$ \\
LES (grid M2) & $+2.40 \%$ & $+0.70 \%$ & $+2.95 \%$ \\
URANS (without transition) & $+2.50 \%$ & $-1.40 \%$ & $-2.90 \%$ \\
URANS (with transition) & $-0.40 \%$ & $-0.05 \%$ & $-0.75 \%$ \\
\hline
\end{tabular}

Table 5: Mean performance at nominal operating conditions. The values predicted by the numerical simulations are expressed as a difference with experimental values.

coarsest grid to the finest one) and 3) both URANS and LES fail to predict accurately the experimental performance curve. The reasons to explain the discrepancies with measurements are still unclear, but what must be kept in mind is that the simulated compressor does not include some of the technological effects of the experimental test rig (for instance, the leakage flows between fix and rotating parts of the hub tend to minimize both efficiency and pressure ratio $[40,47])$. The use of an adiabatic wall boundary condition at the casing can also be criticized, since it can affect the global efficiency by more than 1 percent [7].

To highlight the differences between URANS and LES, a comparison of the time-averaged axial velocity flow fields at rotor/stator interface is shown in Fig. 10. The data are extracted from LES (grid M2) and URANS (with transition modelling) database. The location as well as the velocity deficit induced by the stator potential effects are in good agreement on the whole span. The main difference is observed in the stator pressure side / casing corner where LES shows a lower velocity deficit than predicted with URANS. 
(a)

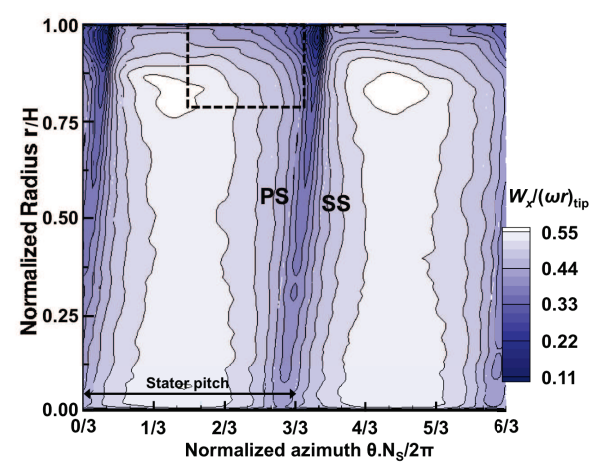

(b)

(c)

Figure 10: Time-averaged 2D flow fields of axial velocity $W_{x} /(\omega R)_{t i p}$ at the rotor/stator interface, at $x=78 \mathrm{~mm}$ (nominal operating point): a) LES (grid M2), b) URANS with transition modelling. The dashed box points out the region where the tip leakage flow modifies the main flow.

Time-averaged axial velocity signals are extracted at $50 \%$ and $80 \%$ of the span and compared with experimental data in Fig. 11. At 50\% of the span, both LES and URANS match well the shape of experimental profiles and predict correctly the velocity deficit due to the stator potential effect. LES and URANS underestimates the maximum axial velocity in the main flow, resp. by $3 \%$ and $4 \%$ (in the case of LES, it corresponds to the difference observed on the mass flow rate, Table 5). At $80 \%$ of the span, LES matches well the experiments, in terms of shape and value. URANS correctly predicts the velocity deficit in the vicinity of the stator leading edge, but it underpredicts the axial velocity in the main flow by $2 \%$ and it does not reproduce the shape of the experimental data around the maximum velocity.

The evolution of the axial velocity with respect to the time is shown in 
(a)

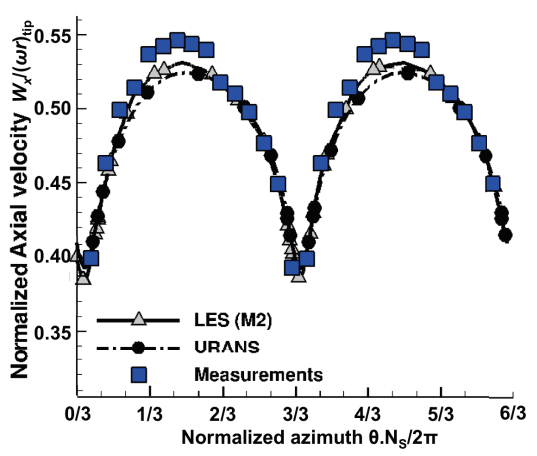

(b)

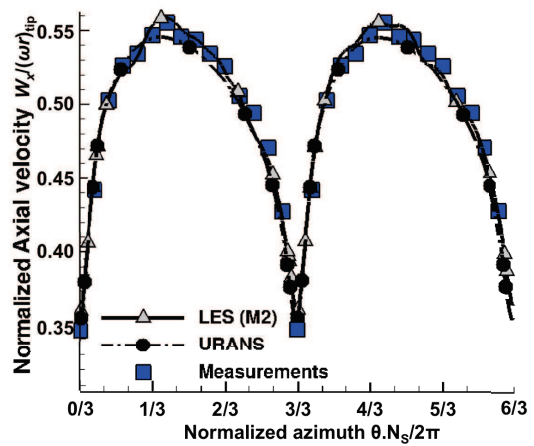

Figure 11: Time-averaged signals of axial velocity $W_{x} /(\omega r)_{t i p}$ at the rotor/stator interface at $x=78 \mathrm{~mm}$ (nominal operating point): a) $h / H=50 \%$ and b) $h / H=80 \%$. Experimental data are extracted from [14].

Fig. 12, at the rotor/stator interface $(x=78 \mathrm{~mm})$ and an azimuth corresponding to the middle of the stator passage $\left(\theta \cdot N_{S} / 2 \pi=0.40\right)$. LES results and experimental data are phase-averaged using the blade passing period. The wake characteristics predicted with LES and URANS are compared to experiments, in terms of depth $D_{\text {wake }}$ (normalized by the tip speed $(\omega R)_{t i p}$ ) and thickness $\theta_{\text {wake }}$ (normalized by the rotor pitch $2 \pi \cdot r / N_{R}$ ), Table 6 . As shown in Fig. 12, the depth is the velocity deficit between the main flow and the minimum velocity inside the wake and the thickness is the "effective size" of the wake corresponding to $W_{x}<\left(W_{x, \text { main }}\right.$ flow $\left.-\sqrt{2} / 2 \times D_{\text {wake }}\right)$.

At mid-span, the discrepancies between LES predictions and measurements on the wake thickness and depth (velocity deficit) are resp. $-10 \%$ and $-10 \%$. For URANS, these discrepancies are resp. $+25 \%$ and $+20 \%$. Close to the casing $(h / H=80 \%)$, both LES and experimental measurements show 
a reduction of the rotor wake thickness and depth, while URANS predicts an increase of its thickness and no modification on the depth. For LES, the discrepancies with measurements on thickness and depth are resp. $-15 \%$ and $-10 \%$. URANS does not capture the good tendency close to the casing: at $h / H=80 \%$ discrepancies on thickness and depth increase to resp. $-65 \%$ and $-30 \%$. LES underpredicts the size of the rotor wake while URANS overpredicts it. However, LES provides data closer to experimental values than URANS, especially close to the casing.

(a)

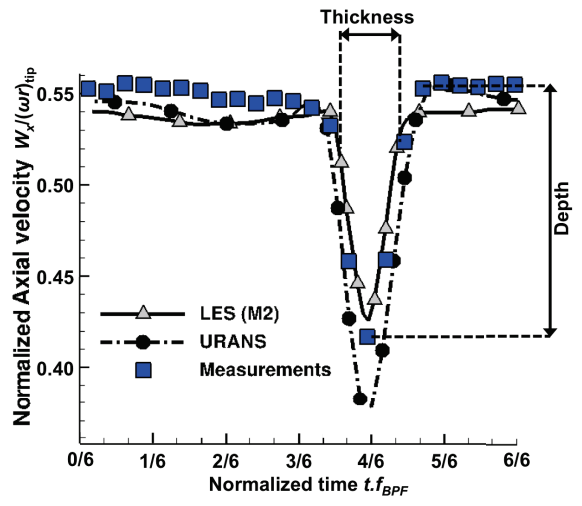

(b)

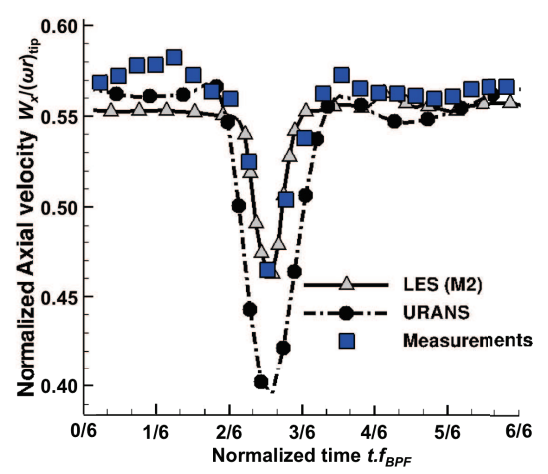

Figure 12: Time-dependent, phase-averaged, signals of axial velocity $W_{x} /(\omega r)_{t i p}$ at the rotor/stator interface, at $x=78 \mathrm{~mm}$ in the middle of the stator passage: a) $h / H=50 \%$ and b) $h / H=80 \%$.

\section{CONCLUSION}

This paper relates the investigations done to simulate the turbulent compressible flow in a stage of an axial compressor, at Reynolds number $R e=$ 


\begin{tabular}{r|cc|cc} 
& \multicolumn{2}{|c|}{ Depth $\left[D_{\text {wake }} /(\omega R)_{\text {tip }}\right]$} & \multicolumn{2}{|c}{ Thickness $\left[\theta_{\text {wake }} /\left(2 \pi . r / N_{R}\right)\right]$} \\
& $h / H=50 \%$ & $h / H=80 \%$ & $h / H=50 \%$ & $h / H=80 \%$ \\
\hline Experiments & 0.13 & 0.10 & 0.14 & 0.12 \\
LES & $-10 \%$ & $-15 \%$ & $-10 \%$ & $-10 \%$ \\
URANS & $+25 \%$ & $+65 \%$ & $+20 \%$ & $+30 \%$ \\
\hline
\end{tabular}

Table 6: Evaluation of the rotor wake characteristics at the rotor/stator interface $(x=78 \mathrm{~mm})$, at nominal operating conditions. The values predicted by the numerical simulations are expressed as a difference with experimental values.

$7 \times 10^{5}$ which is relevant to industrial applications. Two numerical methods have been tested: URANS and LES. The simulation cost ratio, in terms of CPU hours, between URANS and LES on the finest grid (about $10^{9}$ points) is 500 .

A particular care has been brought on the LES grid to ensure academic criteria $\left(\Delta s^{+}<150, n^{+}<1\right.$ and $\left.\Delta r^{+}<40\right)$ recommended for wall-resolved flows. However, the grid sensitivity study conducted in this paper fails to validate these criteria, which are probably not restrictive enough for complex geometries and flows as encountered in turbomachinery (pressure gradient, rotation effects, etc.). Further work is thus mandatory to provide guidelines for such wall-resolved LES. The results also indicate that transition in the rotor occurs at mid-chord, which is in contradiction with the assumption of fully turbulent boundary layers, often used at such Reynolds numbers. At nominal operating conditions, the influence of transition on the efficiency reaches $2 \%$.

The comparison with measurements shows that both URANS and LES correctly estimate the time-averaged quantities at mid-span. This study also 
confirms that LES better predicts the unsteady flow features than URANS, especially near the casing. However, LES doesn't improve the prediction of the mean performance (efficiency and pressure ratio) compared to URANS.

The conclusion of this paper is that LES opens a "Pandora's box": while it has the potential to improve the quality of numerical predictions for turbomachinery flows, it is also much more sensitive to "details" than URANS. Indeed, further works is needed to improve the accuracy of LES, by investigating the role of real geometry effects and boundary conditions (inflow turbulence, adiabatic walls, wall roughness, etc.). The knowledge of boundary conditions requires to work in a more integrated fashion with people doing the experiments.

\section{Acknowledgment}

This work has benefited from the help of a lot of people. First, many thanks to H. Miton from Institut Jean Le Rond d'Alembert for providing experimental data. The author is also grateful to SAFRAN (with a special mention to M. Dumas and G. Leroy for their constant help and support). Thanks also to Pr. M. Manna (University of Naples) for suggesting some of the post-processings performed in this work. The author also thank the CFD team of CERFACS (with special thanks to J.-F. Boussuge and F. Sicot for reading the manuscript and T. Leonard and A. Gomar for their help on post-processing). This work has benefited from CERFACS internal and GENCI-TGCC computing facilities (under the project gen6074). ONERA 
also provided help and support for the CFD code elsA. These supports are greatly acknowledged. Actually, the author would like to express his sympathy and friendship to the turbomachinery team of LMFA at Ecole Centrale de Lyon. This paper is dedicated to Pr. Francis Leboeuf.

\section{References}

[1] B.J. Abu-Ghannam and R. Shaw. Natural transition of boundary layers - the effects of turbulence, pressure gradient, and flow history. J. of Mechanical Engineering Science, 22(5):213-228, 1980.

[2] D. Arnaud, X. Ottavy, and A. Vouillarmet. Experimental investigation of the rotor-stator interactions within a high-speed, multi-stage, axial compressor. part 1 - experimental facilities and results. In ASME Turbo Expo, paper GT2004-53764, 2004.

[3] D. Arnaud, X. Ottavy, and A. Vouillarmet. Experimental investigation of the rotor-stator interactions within a high-speed, multi-stage, axial compressor. part 2 - modal analysis of the interactions. In ASME Turbo Expo, paper GT2004-53778, 2004.

[4] A. Benyahia and R. Houdeville. Transition prediction in transonic turbine configurations using a correlation-based transport equation model. Int. J. of Engineering Systems Modelling and Simulation, 3(1):36-45, 2011. 
[5] R. Bhaskaran and S. K. Lele. Large eddy simulation of free stream turbulence effects on heat transfer to a high-pressure turbine cascade. J. of Turbulence, 11(6), 2010.

[6] J. Boudet, J. Caro, L. Shao, and E. Leveque. Numerical studies towards practical Large-Eddy Simulation. J. Thermal Science, 16(4), 2007.

[7] D. Brunar and M. G. Turner. Isothermal boundary condition at casing applied to the rotor 37 transonic axial flow compressor. J. Turbomach., 135(3), 2013.

[8] L. Cambier, S. Heib, and S. Plot. The Onera ElsA CFD software: Input from research and feedback from industry. Mechanics and Industry, 14:159-174, 2013.

[9] A. J. Crook, E. M. Greitzer, C. S. Tan, and J. J. Adamczyk. Numerical simulation of compressor endwall and casing treatment flow phenomena. J. Turbomach., 115(3), 1993.

[10] I. J. Day. The fundamentals of stall and surge. part 1: Stall. part 2: Surge. In Advances in Axial Compressors Aerodynamics, VKI Lecture Series, 2006.

[11] J. de Laborderie, H. Posson, and S. Moreau. Comparison between urans simulations and an analytical model for predicting the blade pressure distribution. In European Turbomachinery Conference, number 204, 2009 
[12] O. Domercq and J.-F. Escuret. Tip clearance effect on high-pressure compressor stage matching. J. Power and Energy, 221(6), 2007.

[13] F. Duchaine, S. Mendez, F. Nicoud, A. Corpron, V. Moureau, and T. Poinsot. Coupling heat transfer solvers and large eddy simulations for combustion applications. Int. J. of Heat and Fluid Flow, 30:1129-1141, 2009 .

[14] T. M. Faure, G.-J. Michon, H. Miton, and Vassilieff. Laser doppler anemometry measurement in an axial compressor stage. J. Propulsion and Power, 17(3), 2001.

[15] B. Francois, M. Costes, and G. Dufour. Comparison of chimera and sliding mesh techniques for unsteady simulations of counter rotating open-rotors. In 20th ISABE, paper 1231, 2011.

[16] N. Gourdain, S. Burguburu, F. Leboeuf, and G-J. Michon. Simulation of rotating stall in a whole stage of an axial compressor. J. Computer and Fluids, 39(9):1644-1655, 2010.

[17] N. Gourdain, L. Gicquel, M. Montagnac, O. Vermorel, M. Gazaix, G. Staffelbach, M. Garcia, J-F. Boussuge, and T. Poinsot. High performance parallel computing of flows in complex geometries - part 1: Methods. J. of Computational Sciences and Discovery, 2(015003), 2009.

[18] N. Gourdain, L. Y. M. Gicquel, and E. Collado. Comparison of RANS 
and LES for prediction of wall heat transfer in a highly loaded turbine guide vane. J. Propulsion and Power, 28(2):423-433, 2012.

[19] N. Gourdain and F. Leboeuf. Unsteady simulation of an axial compressor stage with casing and blade passive treatments. J. Turbomach., 131(2), 2009.

[20] N. Gourdain, M. Montagnac, F. Wlassow, and M. Gazaix. Highperformance computing to simulate large-scale industrial flows in multistage compressors. Int. J. of High Performance Computing Applications, 24(4), 2010.

[21] N. Gourdain, F. Wlassow, and X. Ottavy. Effect of tip clearance dimensions and control of unsteady flows in a multi-stage high-pressure compressor. J. Turbomach., 134(5):051005, 2012.

[22] B. Greschner and F. Thiele. Wall modeled LES simulation of rotorstator-cascade broadband noise. In 17th AIAA/CEAS Aeroacoustics Conference, paper 2873, 2011.

[23] C. Hah. Large Eddy Simulation of transonic flow field in NASA rotor 37. Technical Report TM-2009-215627, NASA Glenn Research Center, 2009.

[24] M. D. Hathaway. Passive endwall treatments for enhancing stability. In Advances in Axial Compressor Aerodynamics, VKI Lecture Series, 2006. 
[25] M. D. Hathaway and G. Herrick. Unsteady simulation of the stall inception process in the compression system of a us army helicopter gas turbine engine - final year progress. In DoD Users Group Conference, 2005.

[26] M. Inoue, M. Kuroumaru, S. Yoshida, T. Minami, K. Yamada, and M. Furukawa. Effect of tip clearance on stall evolution process in a lowspeed axial compressor stage. In ASME Turbo Expo, paper GT2004$53354,2004$.

[27] A. Jameson. Time dependent calculations using multigrid, with applications to unsteady flows past airfoils and wings. In 10th AIAA Computational Fluid Dynamics Conference, paper 1596, 1991.

[28] N. Jarrin, S. Benhamadouche, D. Laurence, and R. Prosser. A synthetic eddy method for generating inflow conditions for large eddy simulations. Int. J. of Heat and Fluid Flow, 27(4), 2006.

[29] R. B. Langtry, F. R. Menter, S. R. Likki, and Y. B. Suzen. A correlationbased transition model using local variables - part 2: Test cases and industrial applications. J. Turbomach., 128(3), 2006.

[30] M. Manna, C. Benocci, and E. Simons. Large Eddy Simulation of turbulent flows via domain decomposition techniques. part 1: theory. Int. J. Num. Meth. Fluids, 48(4), 2005. 
[31] M. Manna and A. Vacca. Effects of the transverse curvature on the statistics of fully developed turbulent flow in an annular pipe. Int. J. Rotating Machinery, 8(5):353-360, 2002.

[32] R. E. Mayle. The role of laminar-turbulent transition in gas turbine engines. J. Turbomach., 113(4), 1991.

[33] W. A. McMullan and G. J. Page. Towards large eddy simulation of gas turbine compressors. Progress in Aerospace Sciences, 52:30-47, 2012.

[34] F. R. Menter. Two-equation eddy-viscosity turbulence models for engineering applications. AIAA J., 32(8), 1994.

[35] F. R. Menter, R. B. Langtry, S. R. Likki, and Y. B. Suzen. A correlationbased transition model using local variables - part 1: Model formulation. J. Turbomach., 128(3), 2006.

[36] G.-J. Michon, H. Miton, and N. Ouayahya. Unsteady three-dimensional off-design velocity and reynolds stresses in an axial subsonic compressor. J. Propulsion and Power, 21(6), 2005.

[37] F. Nicoud and F. Ducros. Subgrid-scale stress modelling based on the square of the velocity gradient. Flow, Turb. and Combustion, 62(3):183-200, 1999.

[38] H. Nishikawa, M. Rad, and P. Roe. A third-order fluctuation splitting scheme that preserves potential flow. In 15th AIAA Computational Fluid Dynamics Conference, paper 2001-2595, 2001. 
[39] M. Olausson and L. Eriksson. Rotor wake/stator broadband noise calculations using hybrid RANS/LES and chorochronic buffer zones. In 15th AIAA/CEAS Aeroacoustics Conference, paper 3338, 2009.

[40] X. Ottavy, N. Courtiade, and N. Gourdain. Experimental and computational methods for flow investigation in high-speed multistage compressor. J. Propulsion and Power, 28:1141-1155, 2012.

[41] U. Piomelli and E. Balaras. Wall-layer models for Large-Eddy Simulations. Annu. Rev. Fluid Mech., 34, 2002.

[42] S. B. Pope. Turbulent flows. Cambridge University Press, 2000.

[43] J. Kim R. A. Antonia and L. W. B. Browne. Some characteristics of small-scale turbulence in a turbulent duct flow. J. Fluid Mech., 233:369388, 1991.

[44] M. M. Rai. A Direct Numerical Simulation of turbine rotor-stator interaction. In 39th AIAA Fluid Dynamics Conference, paper 3685, 2009.

[45] P. Sagaut. Large Eddy Simulation for incompressible flows. Scientific computation series. Springer-Verlag, 2000.

[46] P. Schlatter and R. Örlu. Assessment of direct numerical simulation data of turbulent boundary layers. J. Fluid Mechanics, 659:116-126, 2010. 
[47] V. Sharma, B. Aupoix, M. Schvallinger, and H. Gaible. Turbulence modelling effects on off-design predictions for a multi-stage compressor. In 18th ISABE, paper 1183, 2007.

[48] J. Smagorinsky. General circulation experiments with the primitive equations: 1. the basic experiment. Mon. Weather Rev. , 91:99-164, 1963.

[49] B. R. Smith. Prediction of hypersonic shock wave turbulent boundary layer interactions with the k-l two equaton turbulence model. In $A I A A$ 33rd Aerospace Sciences Meeting and Exhibit, 1995.

[50] P. Tucker, S. Eastwood, C. Klostermeier, R. Jefferson-Loveday, J. Tyacke, and Y. Liu. Hybrid LES approach for practical turbomachinery flows - part 1: hierarchy and example simulations. J. Turbomach., $134(2), 2012$.

[51] P. Tucker, S. Eastwood, C. Klostermeier, H. Xia, P. Ray, J. Tyacke, and W. Dawes. Hybrid LES approach for practical turbomachinery flows part 2: further applications. J. Turbomach., 134(2), 2012.

[52] S. Yoon and A. Jameson. An LU-SSOR scheme for the Euler and NavierStokes equations. In 25th AIAA Aerospace Sciences Meeting, paper 0600, 1987.

[53] D. You, M. Wang, P. Moin, and R. Mittal. Large-Eddy Simulation anal- 
ysis of mechanisms for viscous losses in a turbomachinery tip-clearance flow. J. Fluid Mech., 586:177-204, 2007.

[54] B. Zhong and P. G. Tucker. $k-l$ based hybrid LES/RANS approach and its application to heat transfer simulation. Int. J. Numer. Meth. Fluids, 46(10), 2004. 